PAPER • OPEN ACCESS

\section{Factors Affecting the Adoption of Emerging Technologies in the Malaysian Construction Industry}

To cite this article: F Khudzari et al 2021 IOP Conf. Ser.: Earth Environ. Sci. 641012006

View the article online for updates and enhancements.
You may also like

Eliciting project managers' perceptions
regarding economic sustainability
incorporation on construction projects: a
Bloemfontein case study
L Sinxadi and BO Awuzie
Benefits and Drivers of Implementing
Green Building Projects in South Africa
O A Oguntona, O I Akinradewo, D L
Ramorwalo et al.
Construction Digitalisation Tools In South
African Construction Industry: An Added
Advantage
O T Tanga, C O Aigbavboa, O I
Akinradewo et al.

The Electrochemical Society

Avvencing solid state S electrochemical science s tecthology

243rd Meeting with SOFC-XVIII

Boston, MA • May 28 - June 2, 2023

Accelerate scientific discovery!
Learn More \& Register

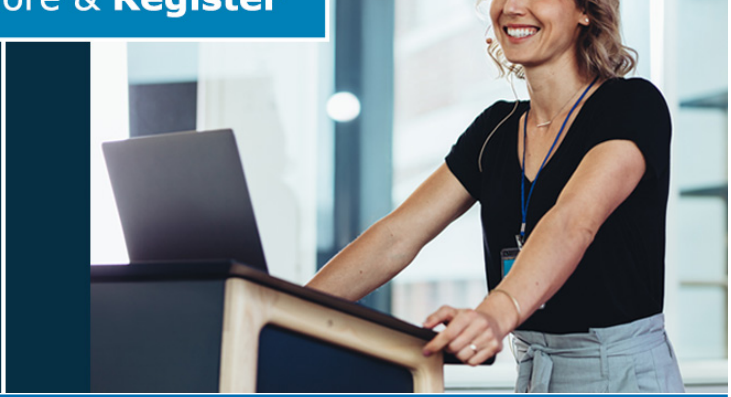




\title{
Factors Affecting the Adoption of Emerging Technologies in the Malaysian Construction Industry
}

\author{
F Khudzari', RA Rahman ${ }^{1,2}$ and SK Ayer ${ }^{3}$ \\ 1 Faculty of Civil Engineering Technology, Universiti Malaysia Pahang, Lebuhraya \\ Tun Razak, 26300 Kuantan, Pahang, Malaysia \\ 2 Earth Resources and Sustainability Centre, Universiti Malaysia Pahang, Lebuhraya \\ Tun Razak, 26300 Kuantan, Pahang, Malaysia \\ 3 School of Sustainable Engineering and Built Environment, Arizona State University, \\ Tempe, Arizona 85281, United States \\ E-mail: arahimirahman@ump.edu.my
}

\begin{abstract}
Technologies are tools or machines that solve real-world problems and, therefore, very important to all industries, including the construction industry. In some parts of the world, technology is a necessity as it helps to improve and increase the efficiency of day-to-day operations, especially in terms of time and budget management. However, there are still many companies that are refusing to apply technology in their construction projects. This study aims to investigate the factors affecting the adoption of emerging technologies in the Malaysian construction industry. To achieve these objectives, this study analyses the extensive interview data with selected construction project managers. Nineteen factors were identified, and these factors can be categorized into two groups (internal; workable by project managers and external; uncontrollable by project managers). This work contributes to the body of knowledge in analysing the factors that affect the adoption of technology in the construction industry from industry practitioners' angle, which could help researchers and industry practitioners draw up plans to reduce the rejection of technologies among the project managers. The findings of this study could help improve the success of adopting the technologies in any part of the construction industry.
\end{abstract}

\section{Introduction}

The Construction Industry Development Board (CIDB) has identified that the significant issues in the Malaysian construction industry are low quality, low productivity, bad visibility, economic instability, uncertainties, staff shortages, and lack of data or knowledge [1]. The low productivity in the sector is due to low technology use, ineffective planning and project, unskilled labour, high input costs, lack of resources in construction post-construction waste, low maintenance, impractical, and accident-prone climate [2]. Almost fifty per cent of construction projects in Malaysia are delayed and causing damage to the client, developer, and the construction sector as a whole because development has a significant economic impact [3]. Therefore, the Malaysian construction industry has to come up with new organizational and efficiency tools sooner or later and thus have a competitive advantage in markets, locally and globally.

Any tools or devices that can solve real-world problems can be categorized as technology. In the construction industry, any combination of resources, processes, and conditions that improves projects 
can be considered as construction technology [4]. Adopting appropriate construction technologies can reduce dependence on labour or human capital and enhance the capacity and efficiency of the construction sector [2]. Construction technology is also useful in handling the safety of construction development [5]. In other words, companies that adopt new technology will acquire significant benefits over those that follow previous practices [2]. Therefore, nowadays, technology is fundamental to the construction industry because it can help solve real-world issues in construction projects.

While adopting technology into the construction world brings many benefits, various factors can hinder the success of adopting these technologies. For example, Building Information Modeling (BIM) is predicted as the future of the construction industry. However, it is undeniable that some of the main barriers to BIM adoption are insufficient professional advice and trained personnel [6]. Another example, a company founded in New York, has developed a bricklaying robot that can lay around 20003000 bricks per day, but construction projects are still using human builders that can lay only around 400-500 bricks [7]. In summary, for decades, while there are promising constructions technologies that have emerged, most of the products, methods, and techniques used in the construction sector have remained mostly unchanged, resulting in an industry plagued by flat profitability, poor safety records, spiraling prices, massive loss of resources and labor shortages [7]. Therefore, it is fundamental to analyze or scrutinize the factors that are affecting the adoption of emerging technologies in construction projects.

This study aimed to explore and identify factors affecting the adoption and implementation of emerging technologies from the perspectives of industry practitioners in the construction industry. The author addresses this goal through an analysis of individual interviews with Malaysian project managers. Besides, the findings of this study offer reference to existing researchers and practitioners in the construction industry for technological successions.

\section{Background}

\subsection{Affecting Factors for Adopting Construction Technology}

According to Sepasgozar \& Bernold (2012), the ability to understand the technology adoption decisionmaking process is crucial when someone seeks to improve the current situation. Construction is generally accepted as a risk-averse sector once it comes to future techniques or new methods, and companies would usually go for technology only after another company, especially a competitor, has already used it successfully. Besides, contractors require empirical evidence from vendors, such as increased productivity, safety, and waste reduction, before adopting construction technology [8].

Technology has simplified the construction process, but not all of these technologies have accomplished productivity gains due to the lack of integration among applications [9]. For example, in Nigeria, the factors affecting BIM adoption are issues like education and training, the availability of software, and the enabling environment, with informed clients interested in using BIM on their projects as being the most significant factors that could help to implement BIM technology [10]. Another example, in the UK, factors affecting the adoption of virtual reality that should be taken into account are organizational, environmental, and project dimensions' factors [11]. On the other hand, a study has identified the attributes of change agents for adopting technologies in construction projects [12]. In other words, the existing body of knowledge lacks information on the affecting factors for adopting technologies in construction projects.

\subsection{Construction Technology in Malaysia}

In Malaysia, CIDB took the initiative of developing tools like the Malaysian Carbon Reduction and Environmental Sustainability Tool (MyCREST) to help industry players integrate construction technology more coherently and seamlessly. Specifically, using this tool can help adopt technology that 
targets the reduction in the number of materials used and waste generated as well as to help more energyefficient buildings, turning construction into one of the technology-driven and environmentally friendly industries. Also, the Malaysian government is prioritizing Industrialized Building System (IBS), an approach that uses prefabrication elements in building construction over most other construction technologies [13]. IBS allows contractors to practice sustainable construction by lowering the number of wastes produced and recycling or reusing certain materials on-site [14]. Other than that, in 2009, in addressing all environmentally related issues, Malaysia has released a green assessment edition known as the Green Building Index (GBI). It is the specific tools and guided step that can steer the Malaysian construction industry in the path of green approach and is designed explicitly for the Malaysian-tropical climate, cultural, social needs, environmental, and development context [15].

\subsection{Positioning this study}

While there are many types of new emerging technology in the construction industry, such as BIM, IBS, and green building, the existing studies have been specific in finding factors affecting the adoption process to a particular type of technology, but none has discussed it generally. There are possibilities that the factors can differ from one another, which means different types of technology have different factors. This study aims to identify the factors affecting the adoption of any emerging technologies in the Malaysian construction industry through individual interviews with industry practitioners. The individual interviews would contribute to the existing studies by offering in-depth perspectives into the root of factors that affect construction technology adoption as a whole. To the best of our knowledge, this is the first work to explore this theme in the literature.

\section{Methodology}

Data collection involves obtaining qualitative data from individual interviews with project managers in the construction sector. The qualitative is analyzed using the method of thematic analysis. The subsequent subsections describe the study's data collection, and data analysis approaches.

\subsection{Data collection}

This study collects data on factors affecting the adoption of emerging technologies in construction projects through open-ended interviews with project managers. Unlike questionnaire surveys, individual interviews allow researchers to clarify, better understand, and analyze the opinions and experiences of the respondents. Open-ended questions allow respondents to provide as much detailed information as they would like [16]. Therefore, we can obtain unique perspectives, practical knowledge, and experiences on the topic. This method of data collection is also applicable in other construction management-related fields, such as in identifying parameters to assess construction readiness of highway construction projects [17] and success factors for design-build projects [18].

The target population of this study is project managers from any civil engineering companies that hold a CIDB grade G7 license as their involvement and decision-making in the projects are very important and crucial, which can affect the success of the projects. Additionally, these G7 companies have a higher tendency to use technologies subjected to more complex projects because, according to CIDB, companies that hold a G7 license can pursue civil engineering construction and building construction projects for an unlimited sum without restrictions (other levels of CIDB license allows projects only up to MYR 10 million, which is roughly USD 2.5 million).

The individual interviews begin with an introduction to the related topic and open-ended question. The question introduced to the participant is: What are the factors that contribute to the success of adopting new technologies in construction projects? What are the challenges you face to adopt the technology in any of the project involved? Also, the interviewees are given additional open-ended questions based on the comments obtained. To understand the interviewees' comments correctly, the collected information needs to be clarified, so the follow-up questions are anticipated to have a more in- 
depth explanation. The interviews will be compiled after each conversation and sent to the respondents for verification.

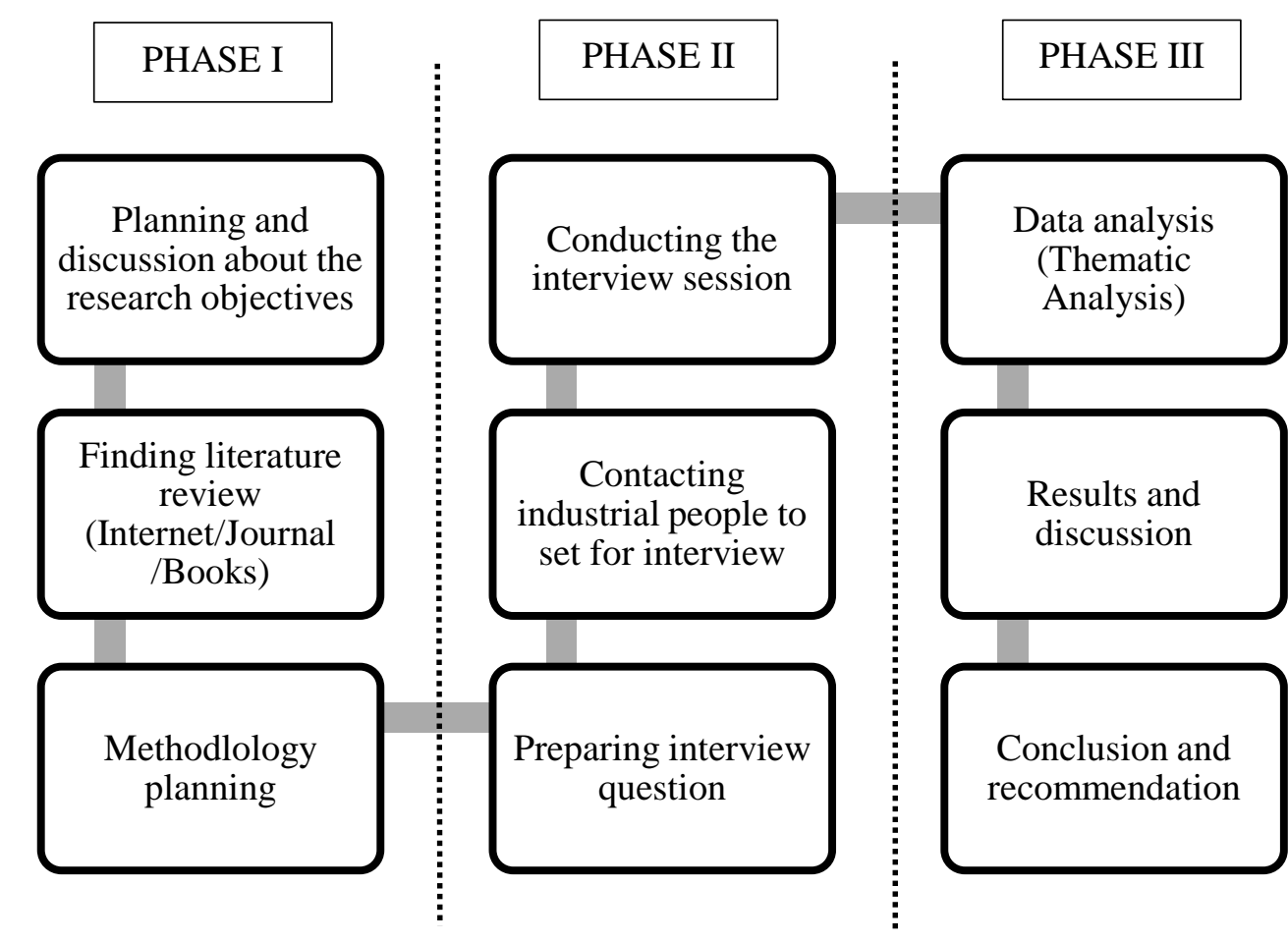

Figure 1. Research Flow Chart.

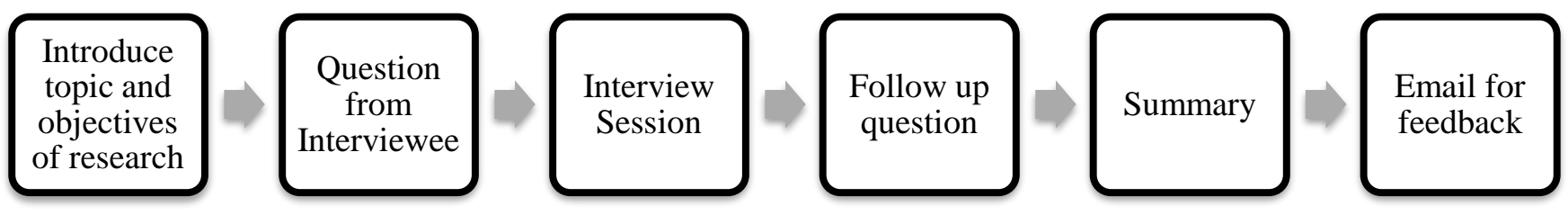

Figure 2. Flow Chart for Interview Session.

\subsection{Data analysis}

The data analysis of performing the thematic analysis as it is a process that can be used with qualitative information and a process of encoding requires codes and maybe in the form of themes [19]. Boyatzis also adds in his book that themes are the trends contained in the information that helps describe, organize, and interprets the theory facets. Other construction management studies are also using the 
thematic analysis to analyze qualitative data, such as in identifying the themes of issues in BIM-based construction projects from data logs [20].

Thematic analysis was performed based on the steps explained by Braun and Clarke (2006). The first step is to become familiar with the data by reading and re-reading the transcripts. At this point, it is also vital to make some notes and identifies early impressions. The second step is to generate initial codes where the information needs to be arranged consistently and meaningfully. The author does not have to code each of the text but instead coded data segment that was relevant and interesting to our research question. The third step is to search for themes. These steps will organize the codes into broader themes driving it more specific to this research question. The fourth step is to review the themes. We will review the themes that have been identified in the third step, whether all the data is relevant to each theme, and did support it. The fifth step is to define the themes where the goal is to classify the essence of each concept. The final one is step six, which is to write the output of the analysis.

\section{Results and discussion}

Figure 1 sum up the factors affecting the adoption of emerging technologies in the construction industry, identified by analyzing data from individual interviews with sixteen project managers involved in the construction industry in Malaysia. In this analysis, the variables are themed from the viewpoint of a project manager into internal and external influences. Internal factors involve parameters that are typically workable by project managers, such as equipment shortages, which can be enhanced through resource management systems, while the external factors are those that are sometimes uncontrollable by project managers, such as delays in progress payment by clients [21]. The internal factors include variables related to labor, cost, time, and technology, while the external factors consist of variables associated with the government and leaders' opinions. These variables are further described in the subsequent subsections.

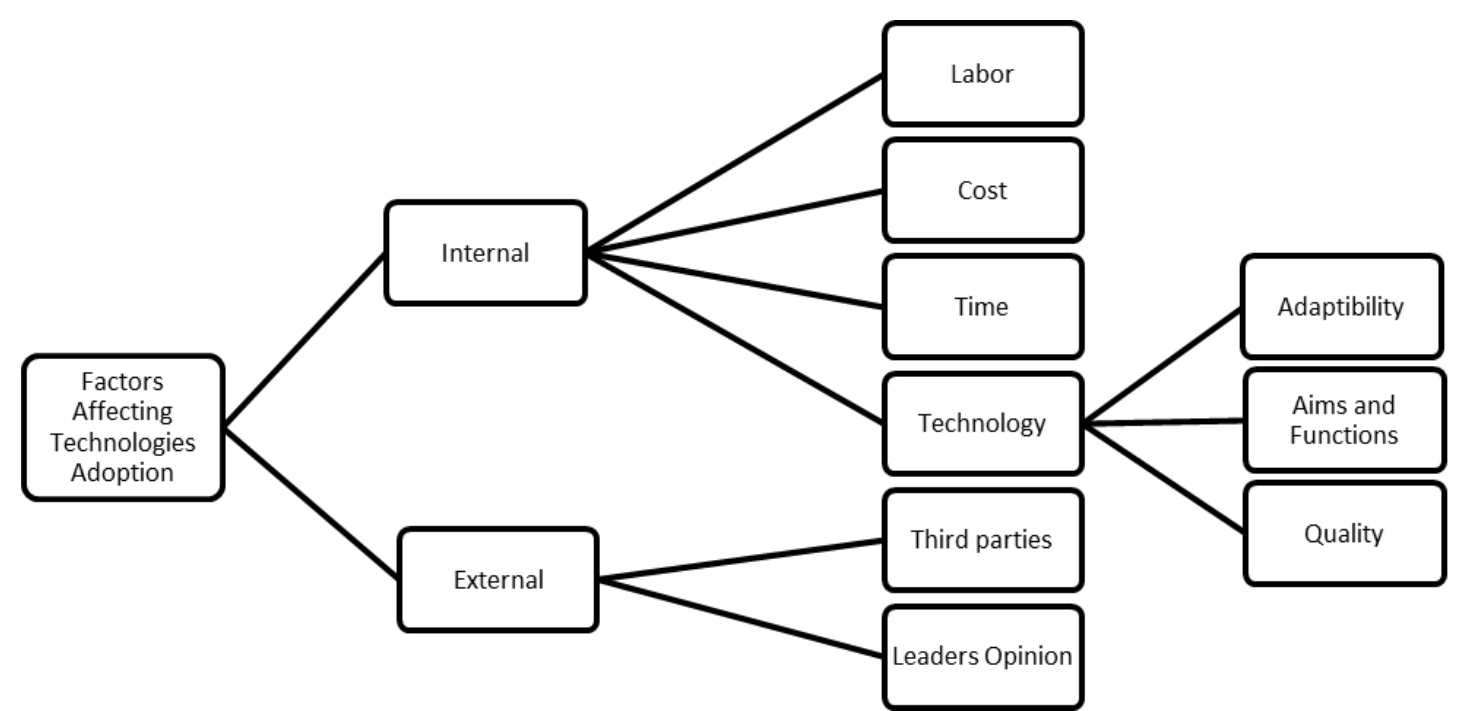

Figure 3. The factors affecting the adoption of emerging technology.

\subsection{Internal Factors Affecting Technologies Adoption in Construction Industry}

\subsubsection{Labor-related internal factors}

Human-related internal factors in this study involve workers' competencies and project stakeholder technology skills. From the analysis of the individual interview with the project managers, the authors find out that labour-related is one of the major factors that can affect the adoption of the technologies in 
the construction industry. Many respondents suggest that the workers' competency plays a vital role in adopting technologies in the construction industry.

Specifically, organizations need someone knowledgeable, enthusiast, and well-trained to handle a particular technology, for example, for assigning a dedicated person to be in charge of the system for updating purpose and also maintaining the accuracy and integrity of the data input. Conversely, several participants suggested that workers with a bad attitude will also affect the technologies adoption process such as there are workers that have been sent for training but did not apply what they have learned in the project. Many workers are good at academic but have no desire to learn to use the new technology that requires more physical training rather than reading and memorizing theories. Thus, to make things work, finding the right person for the right job is significant. Other than that, the respondents also suggest that it is very significant for project stakeholders to have skills in handling technology because they are the person who will plan and schedule the projects, give orders, and lead the team. In other words, to ensure the success of adopting new technologies, both superior and the workers must understand and know how to handle the technology.

\subsubsection{Cost-related internal factors}

Factors for cost-related internal factors involve high costs to adopt technology and the company's desperation to cut costs. Costs will always be an issue in terms of adopting any new type of technology. From the analysis of the individual interview, the participants suggest that the ever-expanding software or new technology equipment puts a high cost to acquire and practice. In other words, to practice a new technology will require a high initial cost. In a study conducted by Eric et al. (2015) shows that the most limiting factors in adopting emerging technology are the initial cost or budget.

Other than that, several participants also said that when contractors are lowering prices for the bidding process, and therefore, the chance of using any new type of technology is low as the company is desperate to cut costs. Participants also said that companies need to have more funds to invest in this new kind of technology. Although the limiting factors for the adoption of new technology are primarily budget-related, as technology prices decrease and productivity returns increase and become more apparent, more and more construction professionals will integrate the technology into their construction process [11].

Table 1. The total number of hits for factors affecting the adoption of emerging technology.

\begin{tabular}{|c|c|c|c|c|c|c|c|c|c|c|c|c|c|c|c|c|c|}
\hline & 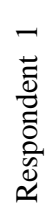 & 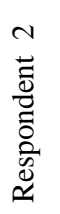 & 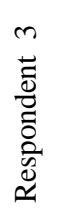 & 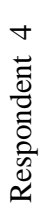 & 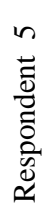 & 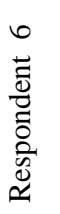 & 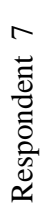 & 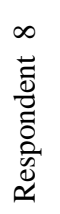 & 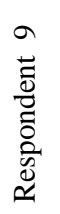 & 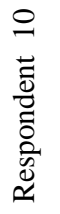 & 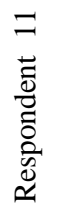 & 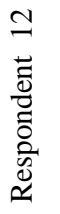 & 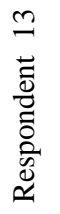 & 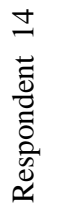 & 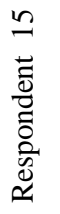 & 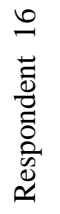 & 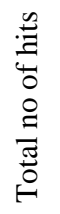 \\
\hline Internal-related factors & & & & & & & & & & & & & & & & & \\
\hline Labour & & & $\sqrt{ }$ & & $\sqrt{ }$ & & $\sqrt{ }$ & $\sqrt{ }$ & $\sqrt{ }$ & $\sqrt{ }$ & $\sqrt{ }$ & $\sqrt{ }$ & & & $\sqrt{ }$ & $\sqrt{ }$ & 10 \\
\hline Cost & & & $\sqrt{ }$ & $\sqrt{ }$ & & & & & & $\sqrt{ }$ & & & $\sqrt{ }$ & & & & 4 \\
\hline Time & & & $\sqrt{ }$ & & & & & & $\sqrt{ }$ & $\sqrt{ }$ & $\sqrt{ }$ & $\sqrt{ }$ & $\sqrt{ }$ & & & & 6 \\
\hline Technology's adaptability & & & & $\sqrt{ }$ & & & $\sqrt{ }$ & & $\sqrt{ }$ & & & & & & & & 3 \\
\hline Aims and functions of technology & & & & & & & $\sqrt{ }$ & & $\sqrt{ }$ & & & $\sqrt{ }$ & $\sqrt{ }$ & & & $\sqrt{ }$ & 5 \\
\hline Technology's quality & & & & & & & & & & & & $\sqrt{ }$ & & & & & 1 \\
\hline $\begin{array}{l}\text { External-related factors } \\
\text { Third parties }\end{array}$ & & & & & $\sqrt{ }$ & $\sqrt{ }$ & & $\sqrt{ }$ & $\sqrt{ }$ & $\sqrt{ }$ & & $\sqrt{ }$ & $\sqrt{ }$ & $\sqrt{ }$ & & & 8 \\
\hline Leaders opinion & $\sqrt{ }$ & & & & & $\sqrt{ }$ & & & & & & $\sqrt{ }$ & $\sqrt{ }$ & $\sqrt{ }$ & & & 5 \\
\hline
\end{tabular}




\subsubsection{Time-related internal factors}

Factors for time-related internal factors involve a more extended time needed to apply those emerging technology in construction projects. Respondents suggest that the company should give their workers early training as it will require a long training duration to master the understanding of the operation and the usefulness of the technology. Besides, respondents also claimed that the company tends to employ foreign workers that have pay grades lower than locals but unfamiliar in advance technology. Having foreign workers that are not technology literature will require employers to provide training that will involve more time to do so.

\subsubsection{Technology's adaptability-related internal factors}

Factors for technology's adaptability-related internal factors involve technologies that are easy to use and adaptable in any situation or even geographical condition. In the interview analysis, participants suggest that technology that can give success in its adoption process must be adaptable, easy to use by the workforce. If it is software, the system must be user-friendly, which means easy to access or to retrieve any information when needed. Some of the participants also said that the technology does not need to be easy to use but relatively user-friendly.

\subsubsection{Aims and function of technology-related internal factors}

Factors for aims and function of technology-related internal factors involve related functions and features, multipurpose types of technology, and technology that can bring everybody on the projects together. First, the new technology's functions and features should directly relate to the field, which can serve its purpose and must comply and parallel with the Malaysian standards and guidelines. Second, respondents suggest that it will affect the adoption process positively if it is a multipurpose type of technology. For example, a technology that can do both bricklaying and plastering at the same time because this will make the process more efficient and will reduce cost and time. Next, respondents also suggest that it will make things better if the technology can bring all the stakeholders together from the early stage to the end of the construction to minimize changes and mistakes.

\subsubsection{Technology's quality-related internal factors}

Factors for technology's quality-related internal factors involve technology that can affect the quality of the projects or the products itself. One respondent claimed that there is a technology that can harm the quality of the products, such as when using the IBS, contractors will face problems like walls cracking all over places.

\subsection{External Factors Affecting Technologies Adoption in Construction Industry}

\subsubsection{Third party-related external factors}

Third parties that are suggested by the participants that can give effect to the success of adopting new technologies include the government and other essential bodies that involve in building development and education department. There are many approaches to achieve that, including; the government can influence success by creating awareness about the use of technology among owners, developers, consultants, and contractors. They also suggest that the government can always support and encourage them using those emerging technologies by giving incentives such as free training and tax-cutting. Also, some of them suggest that the government needs to do further research to identify which stage is the most suitable and practical to apply the technology according to the Malaysian standards and environment and set the guidelines for the company to follow. Then another third-party that can play a more prominent role and obliquely involved are government agencies such as CIDB by promoting A particular technology and its benefits to the industry. 


\subsubsection{Leader's opinion-related external factors}

Factors leader's opinion-related external factors involve convincing the stakeholders on the technology benefits, open up business opportunities, and ensuring the continued use of technology. From the analysis of individual interviews with the sixteen project managers, some of them claimed that it is very challenging to convince the consultants and developers that the technology used will bring many benefits to many parties as they tend to look away when "high cost" is mentioned. In a study conducted by Fernandes et al., (2006) on the adoption of virtual reality in construction processes said that since the cost of VR technologies is high, it is likely that decision stays with the financial expert instead of the company's technical experts.

Participants also claimed that it is very hard on the early stage when they are facing with the uncertainty whether the new and emerging technologies can deliver better than the conventional technology, whether it can do better in terms of cost, time constraint, and also the schedule. Other than that, it is best if the technology can give business opportunities to the company such as technology that can create income and can be used repeatedly in many projects, so it will be worth it to invest in it.

\section{Conclusion}

This study identifies factors affecting the adoption of technology by analysing interview data with sixteen project managers involved with the construction projects to promote the success of adopting emerging technologies in the Malaysian construction industry. The significant results are:

- Nineteen factors are affecting the adoption of technology in the Malaysian construction industry.

- These factors can be categorized into two groups: internal and external factors.

- Internal factors involve parameters that are generally workable by project managers, while external factors are those that are sometimes uncontrollable by project managers.

This study reveals that the issues that emerged in the implementation of technology in the industry are that they have a lack of knowledge and awareness of technology's adoption in the industry. The oldfashioned way is still widely used in many construction projects, which is time and cost consuming. This study will help generate awareness and knowledge about the importance of technology's adoption by identifying the challenges and success factors in adopting any new type of technology in the Malaysian construction industry. These findings have also highlighted the need to identify opportunities to minimize factors that might adversely affect the technology adoption process. The lesson from this study will thus help the industry to promote the adoption of emerging technologies in the construction sector in Malaysia. The primary theoretical contribution of this research is to provide researchers and practitioners with an array of alternative factors that influence this adoption process.

\section{References}

[1] CIDB Master Plan for OSHA (2004), Master Plan for Occupational Safety and Health in Construction Industry 2005-2010, CIDB, Kuala Lumpur.

[2] Razak Bin Ibrahim A, Roy MH, Ahmed Z and Imtiaz G 2010. An Investigation of the Status of The Malaysian Construction Industry. Benchmarking: An International Journal. 17(2) p 294-308.

[3] Abdul-Rahman H, Berawi MA, Berawi AR, Mohamed O, Othman M and Yahya IA, 2006. Delay Mitigation in the Malaysian Construction Industry . Journal of Construction Engineering and Management. 132(2) p 125-133.

[4] Tatum CB 1988. Classification System for Construction Technology. Journal of Construction Engineering and Management. 114(3) p 344-63.

[5] Zhou Z, Irizarry J and Li Q 2013. Applying Advanced Technology to Improve Safety Management in The Construction Industry: A literature review. Construction Management and Economics. 31(6) p 606-22. 
[6] Rogers J,Chong H-Yand Preece C 2015. Adoption of Building Information Modelling (BIM) Technology. Engineering, Construction and Architectural Management. 22(4) p 424-445.

[7] Bogue R, 2018. What are the prospects for robots in the construction industry? Industrial Robot: An International Journal. 45(1) p 1-6.

[8] Sepasgozar SME and Bernold LE 2012. Factors Influencing the Decision of Technology Adoption in Construction. International Conference on Sustainable Design, Engineering and Construction.

[9] Eric A Holt, James M Benham and Ben F Bigelow 2015. Emerging Technology in the Construction Industry: Perceptions from Construction Industry Professionals. $122^{\text {nd }}$ ASEE Annual Conference and Exposition.

[10] Abubakar M, Ibrahim YM, Kado D and Bala K, 2014. Contractors Perception of the Factors Affecting Building Information Modelling (BIM) Adoption in the Nigerian Construction Industry. ASCE 2014.

[11] Fernandes KJ, Raja V, White A and Tsinopoulos C-D 2006. Adoption of Virtual Reality Within Construction Processes: A Factor Analysis Approach. Technovation. 26(1) p 111-120.

[12] Radzi, A. R., Bokhari, H. R., Rahman, R. A. and Ayer, S. K., 2019. Key Attributes of Change Agents for Successful Technology Adoptions in Construction Companies: A Thematic Analysis. In Computing in Civil Engineering 2019: Data, Sensing, and Analytics (pp. 430-437). Reston, VA: American Society of Civil Engineers.

[13] Musa MF, Mohammad MF, Mahbub R and Yusof MR 2014. Enhancing the Quality of Life by Adopting Sustainable Modular Industrialised Building System (IBS) in the Malaysian Construction Industry. Procedia - Social and Behavioral Sciences. 153 p 79-89.

[14] Papargyropoulou E, Preece C, Padfield R and Adila Abdullah A 2011. Sustainable Construction Waste Management in Malaysia: A Contractor's Perspective. Management and Innovation for a Sustainable Built Environment.

[15] Sim YL and Putuhena FJ 2015. Green Building Technology Initiatives to Achieve Construction Quality and Environmental Sustainability in the Construction Industry in Malaysia. Management of Environmental Quality: An International Journal. 26(2) p 233-49.

[16] Turner DW III, 2010. Qualitative Interview Design: A Practical Guide for Novice Investigators. The Qualitative Report. 15(3) p 754-760.

[17] Radzi, A. R., Rahman, R. A., Doh, S. I. and Esa, M., 2020, January. Construction readiness parameters for highway projects. In IOP Conference Series: Materials Science and Engineering (Vol. 712, No. 1, p. 012029). IOP Publishing.

[18] Lee, Z.P., Rahman, R.A. and Doh, S.I., 2020, January. Success Factors of Design-Build Public Sector Projects in Malaysia. In IOP Conference Series: Materials Science and Engineering (Vol. 712, No. 1, p. 012045). IOP Publishing.

[19] Boyatzis R (1998). Transforming Qualitative Information: Thematic Analysis and Code Development.

[20] Rahman, R.A. and Ayer, S. K., 2017. Prevalent issues in BIM-based construction projects. In Proceedings of Joint Conference on Computing in Construction (Vol. 1, pp. 645-652).

[21] Rahman RA, Radzi AR, Saad MSH and Doh SI 2020. Factors Affecting the Success of Highway Construction Projects: The Case of Malaysia. IOP Conference Series: Materials Science and Engineering. 712 p 012030.

[22] Clarke V, Braun V 2015. Thematic Analysis. In: Qualitative Psychology: A Practical Guide to Research Methods. SAGE Publications. p 222

[23] Braun V, Clarke V 2006. Using Thematic Analysis in Psychology. Qualitative Research in Psychology. 3(2) p 77-101.

\section{Acknowledgments}

The authors wish to thank Universiti Malaysia Pahang for supporting this study through financial grant RDU181110 as well as project managers that agreed to participate and providing insights that help 
International Conference of Sustainable Earth Resources Engineering 2020

IOP Publishing

IOP Conf. Series: Earth and Environmental Science 641 (2021) 012006 doi:10.1088/1755-1315/641/1/012006

improve this research 